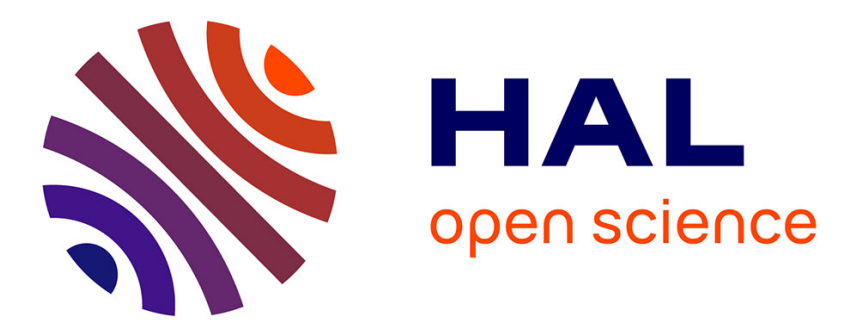

\title{
Optical properties of (GeSe2)100-x(Sb2Se3)x glasses in near- and middle-infrared spectral regions
}

Petr Němec, M. Olivier, Emeline Baudet, Andrea Kalendova, Petr Benda, Virginie Nazabal

\section{- To cite this version:}

Petr Němec, M. Olivier, Emeline Baudet, Andrea Kalendova, Petr Benda, et al.. Optical properties of (GeSe2)100-x(Sb2Se3)x glasses in near- and middle-infrared spectral regions. Materials Research Bulletin, 2014, 51, pp.176-179. 10.1016/j.materresbull.2013.11.050 . hal-01001870

\section{HAL Id: hal-01001870 https://hal.science/hal-01001870}

Submitted on 5 Jun 2014

HAL is a multi-disciplinary open access archive for the deposit and dissemination of scientific research documents, whether they are published or not. The documents may come from teaching and research institutions in France or abroad, or from public or private research centers.
L'archive ouverte pluridisciplinaire HAL, est destinée au dépôt et à la diffusion de documents scientifiques de niveau recherche, publiés ou non, émanant des établissements d'enseignement et de recherche français ou étrangers, des laboratoires publics ou privés. 


\title{
Optical properties of $\left(\mathrm{GeSe}_{2}\right)_{100-\mathrm{x}}\left(\mathrm{Sb}_{2} \mathrm{Se}_{3}\right)_{\mathrm{x}}$ glasses in near- and middle-infrared spectral regions
}

P. Němec (1), M. Olivier (1), E. Baudet (2), A. Kalendová (3), P. Benda (3), V. Nazabal (1, 2)

${ }^{1}$ Department of Graphic Arts and Photophysics, Faculty of Chemical Technology, University of Pardubice, Studentská 573, 53210 Pardubice, Czech Republic

${ }^{2}$ Institut des sciences chimiques de Rennes, UMR CNRS 6226, Equipe Verres et Céramiques, Université de Rennes1, 35042 Rennes, France

${ }^{3}$ Institute of Chemistry and Technology of Macromolecular Materials, Faculty of Chemical Technology, University of Pardubice, Studentská 573, 53210 Pardubice, Czech Republic

* Corresponding author:

Dr. Virginie Nazabal, e-mail: virginie.nazabal@univ-rennes1, phone: +33 (0)2 23235748

\begin{abstract}
Chalcogenide glasses from Ge-Sb-Se ternary system with different antimony content were fabricated and basic physico-chemical properties (chemical composition, thermal characteristics, density) were evaluated considering the glassy network connectivity. Optical properties of the glasses were heavily studied employing transmission spectroscopy, prism coupling technique, and particularly spectroscopic ellipsometry covering broad spectral range $(0.3-20 \mu \mathrm{m})$. Refractive indices data show very good agreement between ellipsometry and prism coupling techniques in near-infrared range. Moreover, the reliability of infrared spectroscopic ellipsometry was demonstrated for precise determination of refractive index of chalcogenide glasses in near- as well as middle-infrared spectral regions.
\end{abstract}

PACS Codes: 42.70.Km, 42.70.Ce, 42.65.-k, 78.20.-e, 81.05.Gc

Key words: A. glasses, A. chalcogenides, D. optical properties, ellipsometry, mid-infrared 


\section{Introduction}

Chalcogenide glasses, based on $\mathrm{S}$, Se or Te elements in combination with suitable elements from 14. or 15. group of the periodical system ( $\mathrm{Ge}, \mathrm{As}, \mathrm{Sb}$, etc.), are known to present photosensitivity to light exposure [1-4] and to be highly nonlinear [5, 6]. Indeed, they present large Kerr nonlinearities at femtosecond time scale and Their high third order susceptibility $\chi^{(3)}$ can reach values several orders of magnitude larger than that of silica glass [7]. For these reasons, chalcogenide glasses have been studied for ultrafast switching in telecommunication systems [8]. Further, chalcogenide glasses can also be used for optical sensing applications from visible to near mid-IR [9-12]. For mentioned applications, chalcogenide thin films are needed; therefore a key prerequisite is an identification of appropriate bulk glass composition.

The Ge-Sb-Se glassy system is of interest due to its large glass forming region [13] giving a possibility of tailoring glass properties in broad ranges. In comparison with chalcogenide glasses compositions based on arsenic, the use of antimony is beneficial regarding the limitation of arsenic in the glass composition in accordance with the recommendations of the current regulation. Moreover, the substitution of As with Sb may increase the (non)linear refractive of the corresponding amorphous chalcogenides due to enlargement of (hyper)polarisability. Further, presence of antimony in amorphous chalcogenides is known to reduce photosensitivity of the material and this property could be tailored by changing the proportion of $\mathrm{Sb}$.

For applications in photonics, one of the most important optical characteristics of chalcogenide glasses is refractive index. In visible and near-infrared (NIR) spectral region, refractive index is often evaluated by modeling of spectroscopic data (transmission and/or reflection), prism coupling method, ellipsometry or it can be calculated by quantum mechanics, etc. [14]. In this paper, beyond the description of basic physico-chemical properties, we are focused on linear optical properties of selected bulk chalcogenide glasses from Ge-Sb-Se system. This is a required step in order to perfectly master the optical properties of the pseudo-binary $\left(\mathrm{GeSe}_{2}\right)_{100-\mathrm{x}}\left(\mathrm{Sb}_{2} \mathrm{Se}_{3}\right)_{\mathrm{x}}$ system for applications whether in the field of optical sensors or in non-linear optics. Special attention was paid to the use of spectroscopic ellipsometry in broad spectral range with the aim to determine linear refractive index from ultraviolet to middle-infrared (MIR).

\section{Material and methods}


Bulk samples from pseudo-binary $\left(\mathrm{GeSe}_{2}\right)_{100-\mathrm{x}}\left(\mathrm{Sb}_{2} \mathrm{Se}_{3}\right)_{\mathrm{x}}$ system $(5 \leq \mathrm{x} \leq 70)$ were synthesized from elements $(\mathrm{Ge}, \mathrm{Sb}$, and $\mathrm{Se}$ ) of high purity $(5 \mathrm{~N})$ using the conventional melting and quenching technique. After the quenching, glass rods were annealed $\left(20^{\circ} \mathrm{C}\right.$ below their glass transition temperature $\left(\mathrm{T}_{\mathrm{g}}\right), 6$ hours) and slowly cooled down to room temperature. For optical characterization, resulting glass rods (25 mm diameter) were sliced and polished. A scanning electron microscope with an energydispersive X-ray analyzer (EDS, JSM 6400-OXFORD Link INCA) was used for the determination of Ge$\mathrm{Sb}-\mathrm{Se}$ glasses chemical composition and its uniformity. Transmission spectra were recorded in VIS-NIR spectral range with $1 \mathrm{~mm}$ thick samples (Perkin Elmer Lambda 1050 spectrophotometer). After calculation of absorption coefficients, cut-off wavelengths were determined for an absorption coefficient of $10 \mathrm{~cm}^{-1}$. Linear refractive indices of fabricated glasses were measured using the prism coupling technique (Metricon 2010) at 1311 and $1551 \mathrm{~nm}$. Silicon prism was used for these measurements. Linear refractive indices spectral dependencies as well as optical band gap values of $\left(\mathrm{GeSe}_{2}\right)_{100-\mathrm{x}}\left(\mathrm{Sb}_{2} \mathrm{Se}_{3}\right)_{\mathrm{x}}$ glasses were obtained from the analysis of variable angle spectroscopic ellipsometry (VASE) data measured using an ellipsometer with automatic rotating analyzer (J. A. Woollam Co., Inc.). The measurement parameters are as follows: spectral region 300-2300 nm (UV-NIR) with wavelengths steps of $20 \mathrm{~nm}$, angles of incidence $50^{\circ}, 60^{\circ}$, and $70^{\circ}$. For the analysis of VASE data, we used Cody-Lorentz model which includes both the correct band edge function and weak Urbach absorption tail [15]; this model is appropriate for the description of amorphous chalcogenides optical functions [4, 16]. Linear refractive indices were extracted also from spectroscopic ellipsometry data measured in NIR-MIR spectral region with IR-VASE ellipsometer (J. A. Woollam Co., Inc.) exploiting rotating compensator. NIR-MIR ellipsometric data were measured within 1700-20000 nm range using wavelength steps and angles of incidence as above. To derive refractive indices in NIR-MIR spectral range, Cauchy like dispersion relation was exploited, setting extinction coefficient in first approximation to zero.

\section{Results and discussion}

The bulk $\left(\mathrm{GeSe}_{2}\right)_{100-\mathrm{x}}\left(\mathrm{Sb}_{2} \mathrm{Se}_{3}\right)_{\mathrm{x}}$ samples were amorphous as confirmed by X-ray diffraction data, excluding $\left(\mathrm{GeSe}_{2}\right)_{30}\left(\mathrm{Sb}_{2} \mathrm{Se}_{3}\right)_{70}$ material, which was (at least partly) crystalline and was not used for further optical characterization. As determined using EDS, chemical composition of fabricated glasses is in good agreement with nominal one; the differences are about 1 at. \% which correspond to the EDS measurements uncertainty. 
No crystallization peaks were observed in DSC curves except for glass with $\mathrm{x}=70$ which is close to glassy domain edge. $T_{g}$ decreases monotonously when antimony concentration increases (from 360 ${ }^{\circ} \mathrm{C}$ for $\left(\mathrm{GeSe}_{2}\right)_{95}\left(\mathrm{Sb}_{2} \mathrm{Se}_{3}\right)_{5}$ glass to $\sim 230{ }^{\circ} \mathrm{C}$ for $\left(\mathrm{GeSe}_{2}\right)_{40}\left(\mathrm{Sb}_{2} \mathrm{Se}_{3}\right)_{60}$ composition). This trend follows changes of vitreous network connectivity occurring when antimony is incorporated in chalcogenide glasses. We note that antimony coordination is 3 (supposing [ $\left.\mathrm{SbSe}_{3 / 2}\right]$ pyramids as basic structural motifs containing antimony atoms), whereas germanium is known to be in a tetrahedral environment ([GeSe $\left.{ }_{4 / 2}\right]$ tetrahedra) [17-19]. On the other hand, density of $\left(\mathrm{GeSe}_{2}\right)_{100-x}\left(\mathrm{Sb}_{2} \mathrm{Se}_{3}\right)_{\mathrm{x}}$ glasses clearly increases with rising $\mathrm{x}$ (from $\sim 4.35 \mathrm{~g} . \mathrm{cm}^{-3}$ for $\left(\mathrm{GeSe}_{2}\right)_{95}\left(\mathrm{Sb}_{2} \mathrm{Se}_{3}\right)_{5}$ to $\sim 5.24 \mathrm{~g} . \mathrm{cm}^{-3}$ for $\left.\left(\mathrm{GeSe}_{2}\right)_{40}\left(\mathrm{Sb}_{2} \mathrm{Se}_{3}\right)_{60}\right)$. Considering atomic masses of elements $\left(\mathrm{A}_{\mathrm{r}}(\mathrm{Ge})=72.64, \mathrm{~A}_{\mathrm{r}}(\mathrm{Sb})=121.76, \mathrm{~A}_{\mathrm{r}}(\mathrm{Se})=78.96\right)$, the density of glasses increases coherently with $\mathrm{Sb}_{2} \mathrm{Se}_{3}$ introduction [20]. This also tends to prove that the substitution of $\mathrm{GeSe}_{2}$ by $\mathrm{Sb}_{2} \mathrm{Se}_{3}$ (leading to a lower degree of connectivity) does not increase drastically the free volume of the glassy network which should have an antagonistic effect on the density.

Optical transmission of studied glasses reaches $\sim 64 \%$ in the NIR region; this limit comes from Fresnel reflections at air/glass interface. Fig. 1 gives spectral dependences of absorption coefficient calculated from measured transmission spectra. One can see the shift of the fundamental absorption edge to lower energies with increasing content of antimony in the glasses. The influence of atomic orbitals originated from antimony selenide in the band structure of the selenide glass can be easily felt on the optical band-gap. Cut-off wavelengths (described above) of all the glassy samples are given in Table 1 showing similar tendency.

Linear refractive indices of $\left(\mathrm{GeSe}_{2}\right)_{100-\mathrm{x}}\left(\mathrm{Sb}_{2} \mathrm{Se}_{3}\right)_{\mathrm{x}}$ glasses measured at 1311 and $1551 \mathrm{~nm}$ by the prism coupling technique are listed in Table 1. As anticipated, the refractive index rises particularly by increasing the proportion of antimony (from 2.41 for $\left(\mathrm{GeSe}_{2}\right)_{95}\left(\mathrm{Sb}_{2} \mathrm{Se}_{3}\right)_{5}$ glass to 3.01 for $\left(\mathrm{GeSe}_{2}\right)_{40}\left(\mathrm{Sb}_{2} \mathrm{Se}_{3}\right)_{60}$ composition, at $\left.1550 \mathrm{~nm}\right)$. Consequently, one can expect a similar trend for nonlinear refractive index [21]. Spectroscopic ellipsometry data analysis with Cody-Lorentz model provides a determination of refractive indices dispersion over broad spectral range (300-2300 nm) including absorption onset and fundamental absorption of studied chalcogenide glasses, with an uncertainty of $\pm 1.10^{-2}$. The Cody-Lorentz model refractive indices results, illustrated in Fig. 2 and Table 1, are in pretty good agreement with the results obtained by the prism coupling technique even thought that absolute precision is higher for prism coupling $\left( \pm 1.10^{-3}\right)$. Optical band gap values, extracted from VASE data again employing Cody-Lorentz model, are listed in Table 1 confirming the compositional tendency of 
cut-off wavelengths even if absolute values of cut-off energies differ from VASE band gap energies due to different method of calculation.

To date, published refractive index data of chalcogenide glasses/thin films in MIR spectral region are infrequent [22]. This can easily be explained by the fact that apart from traditional glasses, these measurements require specific manufacturing of chalcogenide prism involving perfect homogeneity and appropriate size as well as access to an accurate optical metrology set-up. Also, the fabrication of optical components for MIR is often empirical because their dispersion of refractive indices in MIR have not necessarily been characterized enough accurately. Our data show applicability of spectroscopic ellipsometry for the determination of refractive indices of chalcogenide glasses covering 1700-20000 nm region with simple model used (Fig. 2) for a series of $\left(\mathrm{GeSe}_{2}\right)_{100-\mathrm{x}}\left(\mathrm{Sb}_{2} \mathrm{Se}_{3}\right)_{\mathrm{x}}$ chalcogenide glasses.

For a comparison, we employed IR VASE for a determination of refractive index of commercially available $\mathrm{As}_{2} \mathrm{Se}_{3}$ glass (AMTIR-2, Amorphous Materials Inc.). The results obtained are given in Fig. 3 showing very good agreement between our data and data provided by producer. We point out also excellent consistency of $\mathrm{As}_{2} \mathrm{Se}_{3}$ glass refractive index data (taking into account absolute precision of the methods) between IR VASE and prism coupling technique [22] showing maximal $\Delta \mathrm{n}$ of 0.004 at 3390 nm. Finally, Fig. 3 shows matching of refractive index determined by VASE and producer data for $\mathrm{Ge}_{28} \mathrm{Sb}_{12} \mathrm{Se}_{60}$ bulk glass (IG5, Schott $\left.\mathrm{AG}\right)$; the data again agree very well $(\Delta \mathrm{n}=0.005$ at maximum in MIR). Although VASE does not allow reaching the accuracy obtained in the case of the prism method, the data analysis realized for two commercial selenide glasses validates the measurement method of refractive index by mean of infrared ellipsometry.

\section{Conclusions}

Bulk $\left(\mathrm{GeSe}_{2}\right)_{100-\mathrm{x}}\left(\mathrm{Sb}_{2} \mathrm{Se}_{3}\right)_{\mathrm{x}}$ chalcogenide glasses $(\mathrm{x}=5-60)$ were synthesized in high purity. Glass transition temperatures decrease with increasing antimony content, while densities show opposite tendency. This behavior is connected with the changes of glassy matrix connectivity. The fundamental absorption edge of the glasses shifts to lower energies with increasing content of antimony selenide. On the other hand, linear refractive index is strongly rising at the same moment (from 2.41 for $\left(\mathrm{GeSe}_{2}\right)_{95}\left(\mathrm{Sb}_{2} \mathrm{Se}_{3}\right)_{5}$ glass to 3.01 for $\left(\mathrm{GeSe}_{2}\right)_{40}\left(\mathrm{Sb}_{2} \mathrm{Se}_{3}\right)_{60}$ composition, at $\left.1550 \mathrm{~nm}\right)$. We point out good accordance between refractive indices data extracted from spectroscopic ellipsometry and prism coupling technique. The main finding of this work is the applicability of infrared spectroscopic ellipsometry for 
precise determination of refractive index of chalcogenide glasses (as demonstrated for $\mathrm{As}_{2} \mathrm{Se}_{3}$ and $\mathrm{Ge}_{28} \mathrm{Sb}_{12} \mathrm{Se}_{60}$ glasses) in broad spectral range covering NIR and MIR regions.

\section{Acknowledgements}

The Czech Science Foundation (Project No. 13-05082S) and Ministry of Education, Youth, and Sports of the Czech Republic (Project CZ.1.07/2.3.00/30.0058) and the CNRS PICS (Projet International de Cooperation Scientifique) program financially supported this work.

\section{References}

[1] C. Meneghini, A. Villeneuve, Journal of the Optical Society of America B-Optical Physics, 15 (1998) 2946-2950.

[2] K. Shimakawa, A. Kolobov, S.R. Elliott, Adv. Phys., 44 (1995) 475-588.

[3] N. Ho, J.M. Laniel, R. Vallee, A. Villeneuve, Opt. Lett., 28 (2003) 965-967.

[4] P. Nemec, S. Zhang, V. Nazabal, K. Fedus, G. Boudebs, A. Moreac, M. Cathelinaud, X.-H. Zhang, Opt. Express, 18 (2010) 22944-22957.

[5] G. Lenz, J. Zimmermann, T. Katsufuji, M.E. Lines, H.Y. Hwang, S. Spalter, R.E. Slusher, S.W.

Cheong, J.S. Sanghera, I.D.o.n. Aggarwal, Opt. Lett., 25 (2000) 254-256.

[6] A. Zakery, S.R. Elliott, J. Non-Cryst. Solids, 330 (2003) 1-12.

[7] J.S. Sanghera, C.M. Florea, L.B. Shaw, P. Pureza, V.Q. Nguyen, M. Bashkansky, Z. Dutton, I.D. Aggarwal, J. Non-Cryst. Solids, 354 (2008) 462-467.

[8] B.J. Eggleton, B. Luther-Davies, K. Richardson, Nat. Photonics, 5 (2011) 141-148.

[9] A. Ganjoo, H. Jain, C. Yu, J. Irudayaraj, C.G. Pantano, J. Non-Cryst. Solids, 354 (2008) 2757-2762.

[10] M.L. Anne, J. Keirsse, V. Nazabal, K. Hyodo, S. Inoue, C. Boussard-Pledel, H. Lhermite, J.

Charrier, K. Yanakata, O. Loreal, J. Le Person, F. Colas, C. Compere, B. Bureau, Sensors, 9 (2009) 73987411.

[11] M.A. Schmidt, D.Y. Lei, L. Wondraczek, V. Nazabal, S.A. Maier, Nat Commun, 3 (2012) 1108.

[12] J. Hu, V. Tarasov, A. Agarwal, L. Kimerling, N. Carlie, L. Petit, K. Richardson, Optics Express, 15 (2007) 2307-2314.

[13] M.A. Popescu, Non-Crystalline Chalcogenides, Kluwer Academic Publishers, Dordrecht, (2000). 
[14] E.D. Palik, Handbook of Optical Constants of Solids, Academic Press, San Diego CA, USA, 1997.

[15] G.D. Cody, in: J.I. Pankove (Ed.) Semiconductors and semimetals, Academic, Orlando, FL, 1984, pp. 11.

[16] P. Nemec, V. Nazabal, M. Frumar, J. Appl. Phys., 106 (2009) 023509.

[17] V. Nazabal, F. Charpentier, J.-L. Adam, P. Nemec, H. Lhermite, M.-L. Brandily-Anne, J. Charrier, J.-P. Guin, A. Moreac, Int. J. Appl. Ceram. Technol., 8 (2011) 990-1000.

[18] L. Petit, N. Carlie, K. Richardson, Y. Guo, A. Schulte, B. Campbell, B. Ferreira, S.o.n. Martin, J. Phys. Chem. Solids, 66 (2005) 1788-1794.

[19] K. Jackson, A. Briley, S. Grossman, D.V. Porezag, M.R. Pederson, C. system, Physical Review B, 60 (1999) R14985-R14989.

[20] A. Giridhar, P.S.L. Narasimham, S. Mahadevan, J. Non-Cryst. Solids, 43 (1981) 29-35.

[21] E.M. Vogel, M.J. Weber, D.M.o.n. Krol, Phys. Chem. Glasses, 32 (1991) 231-254.

[22] N. Carlie, N.C. Anheier, H.A. Qiao, B. Bernacki, M.C. Phillips, L. Petit, J.D. Musgraves, K. Richardson, Review of Scientific Instruments, 82 (2011) 053103. 


\section{Figure captions}

Fig. 1. Spectral dependences of absorption coefficient of $\left(\mathrm{GeSe}_{2}\right)_{100-\mathrm{x}}\left(\mathrm{Sb}_{2} \mathrm{Se}_{3}\right)_{\mathrm{x}}$ glasses.

Fig. 2. Refractive index dispersion of bulk $\left(\mathrm{GeSe}_{2}\right)_{100-\mathrm{x}}\left(\mathrm{Sb}_{2} \mathrm{Se}_{3}\right)_{\mathrm{x}}$ glasses obtained by ellipsometry covering UV-VIS-NIR-MIR spectral range: 300-2300 nm (full curves) and 1700-20000 nm (dashed curves). Note that full and dashed curves are overlapped in the region of 1700-2300 nm.

Fig. 3. Refractive index dispersion of bulk $\mathrm{As}_{2} \mathrm{Se}_{3}$ (full curves) and $\mathrm{Ge}_{28} \mathrm{Sb}_{12} \mathrm{Se}_{60}$ (dashed curves) glasses determined by ellipsometry covering UV-VIS-NIR-MIR spectral range (300-20000 nm). For a comparison, data published by producer of commercial $\mathrm{As}_{2} \mathrm{Se}_{3}$ (AMTIR-2) and $\mathrm{Ge}_{28} \mathrm{Sb}_{12} \mathrm{Se}_{60}$ (IG5) glass are given. Inset shows 900-14000 nm spectral range in more detail. 


\section{Table captions}

Table 1. Theoretical chemical composition of fabricated $\left(\mathrm{GeSe}_{2}\right)_{100-\mathrm{x}}\left(\mathrm{Sb}_{2} \mathrm{Se}_{3}\right)_{\mathrm{x}}$ glasses, their cut-off wavelengths (at $10 \mathrm{~cm}^{-1}$ ), refractive indices determined by prism coupling technique (at 1311 and 1551 $\left.\mathrm{nm}, \pm 1.10^{-3}\right)$ and VASE $\left(1550 \mathrm{~nm}, \pm 1.10^{-2}\right)$, and optical band-gap values extracted from VASE data by Cody-Lorentz model $( \pm 0.01 \mathrm{eV})$. 


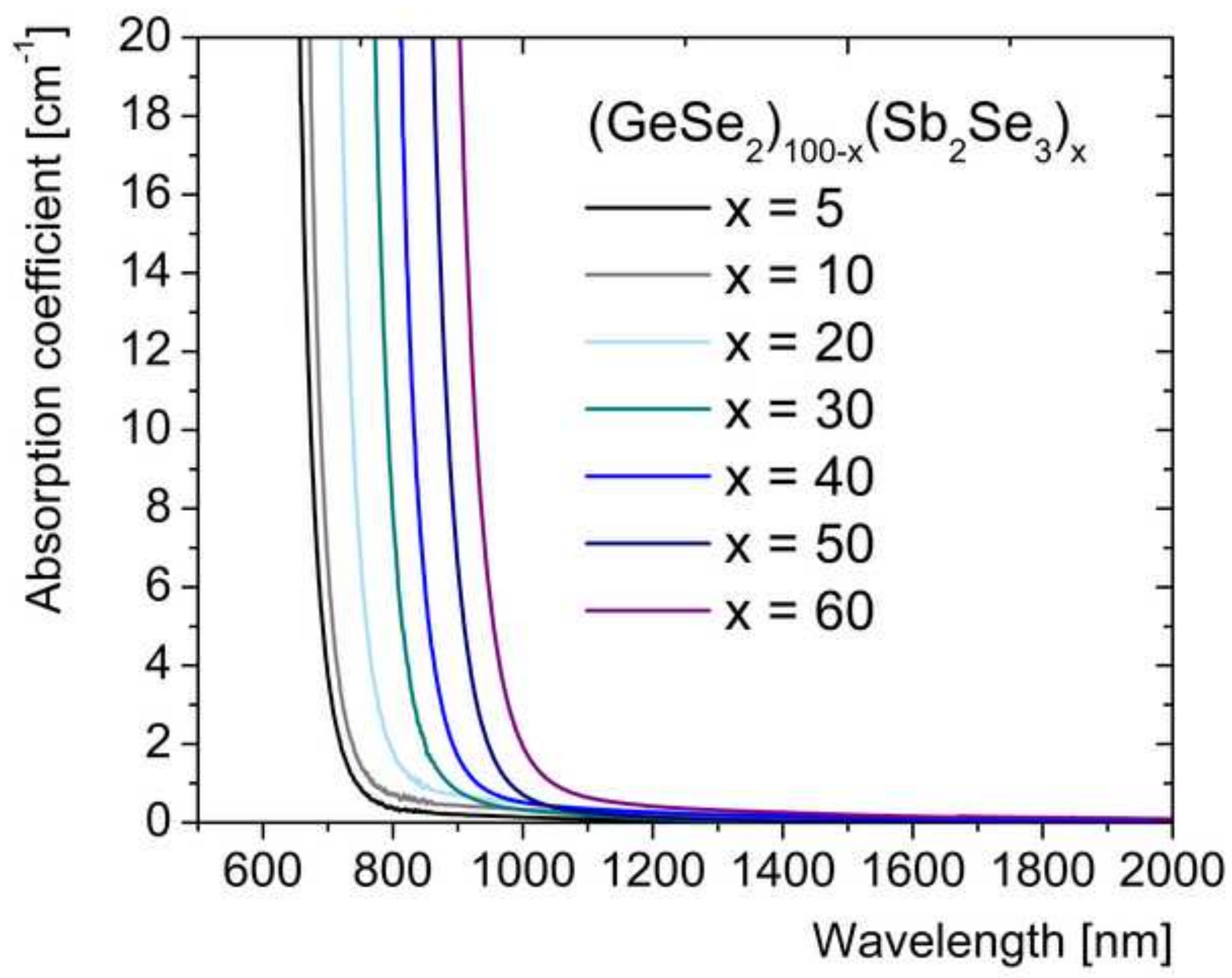




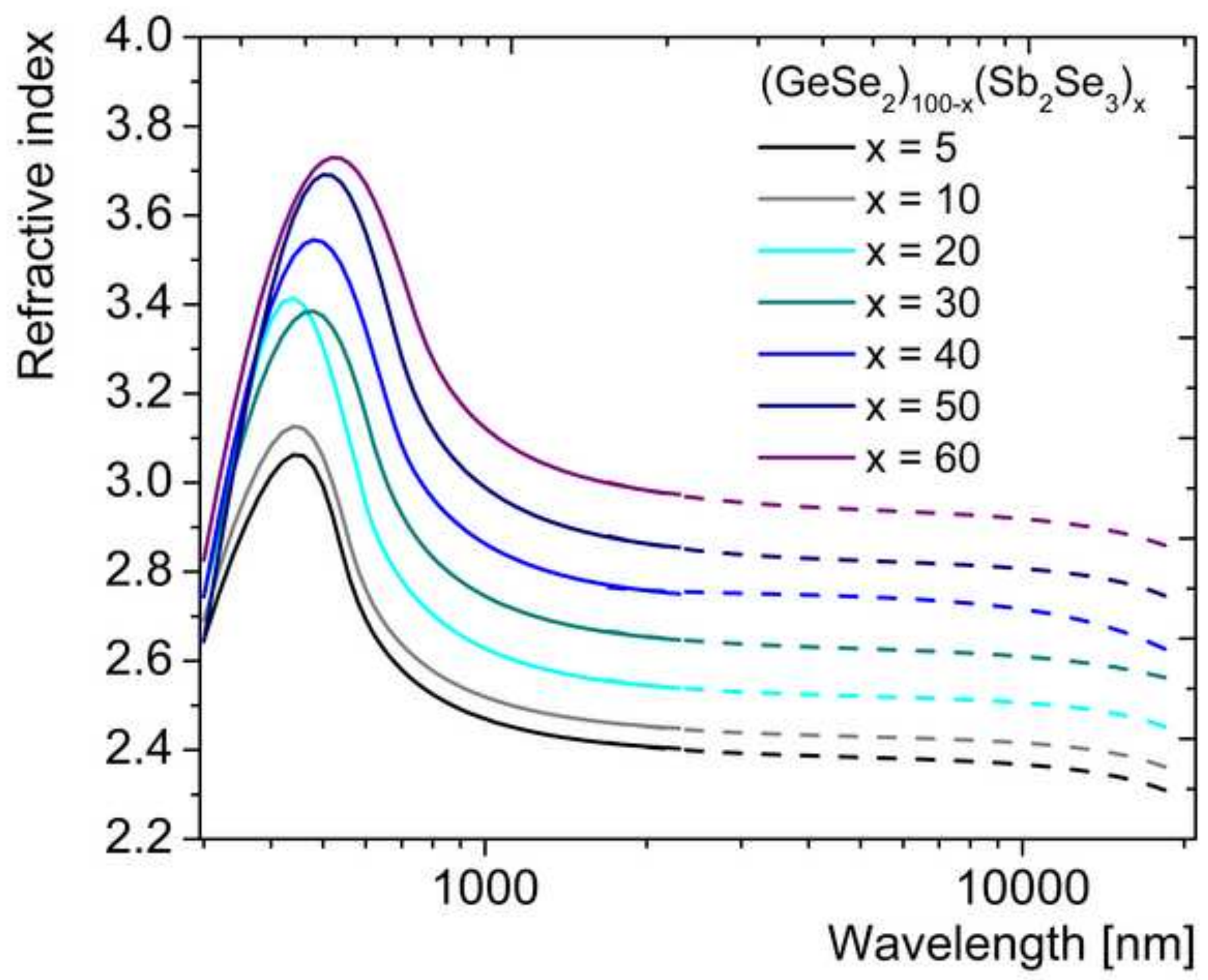




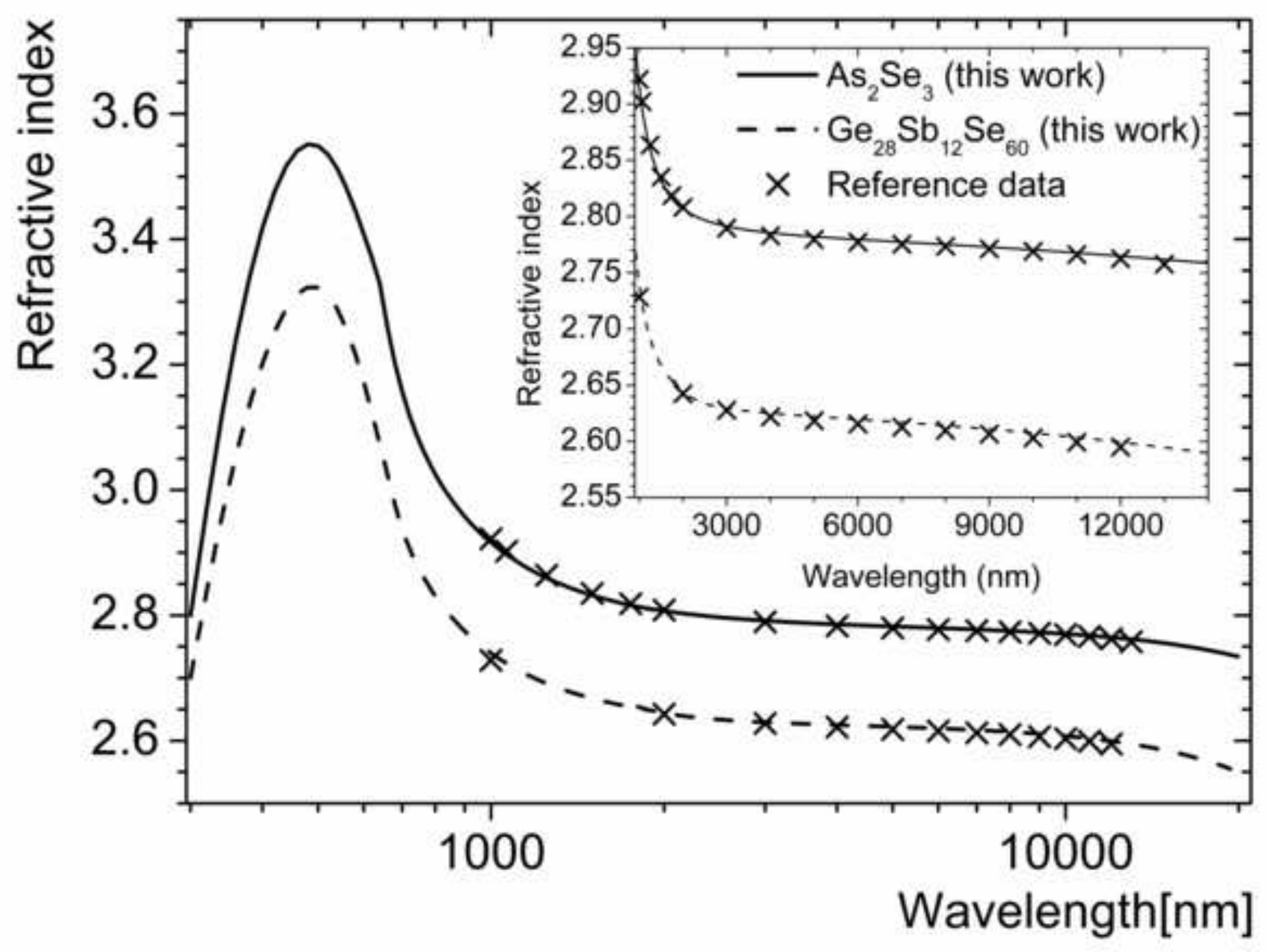


Table 1.

\begin{tabular}{ccccccc}
\hline \multirow{2}{*}{ Sample } & $\begin{array}{c}\text { Theoretical } \\
\text { composition }\end{array}$ & $\begin{array}{c}\text { Cut-off wavelength } \\
\text { (nm) }\end{array}$ & \multicolumn{2}{c}{ n Prism coupling } & n VASE & Eg \\
& $\mathrm{Ge}_{30.6} \mathrm{Sb}_{3.2} \mathrm{Se}_{66.1}$ & 678 & 2.423 & 2.414 & 2.42 & 2.17 \\
\hline $\mathrm{x}=5$ & $\mathrm{Ge}_{28.1} \mathrm{Sb}_{6.3} \mathrm{Se}_{65.6}$ & 689 & 2.483 & 2.471 & 2.47 & 2.11 \\
\hline $\mathrm{x}=10$ & $\mathrm{Ge}_{23.5} \mathrm{Sb}_{11.8} \mathrm{Se}_{64.7}$ & 749 & 2.579 & 2.563 & 2.56 & 2.02 \\
\hline $\mathrm{x}=20$ & $\mathrm{Ge}_{19.4} \mathrm{Sb}_{16.7} \mathrm{Se}_{63.9}$ & 792 & 2.688 & 2.672 & 2.67 & 1.86 \\
\hline $\mathrm{x}=30$ & $\mathrm{Ge}_{1.8} \mathrm{Sb}_{21.1} \mathrm{Se}_{63.2}$ & 843 & 2.801 & 2.780 & 2.78 & 1.78 \\
\hline $\mathrm{x}=40$ & $\mathrm{Ge}_{10}$ & 885 & 2.931 & 2.904 & 2.89 & 1.70 \\
\hline $\mathrm{x}=50$ & $\mathrm{Ge}_{12.5} \mathrm{Sb}_{25} \mathrm{Se}_{62.5}$ & 934 & 3.042 & 3.012 & 3.01 & 1.49 \\
\hline $\mathrm{x}=60$ & $\mathrm{Ge}_{9.5} \mathrm{Sb}_{28.6} \mathrm{Se}_{61.9}$ & 934 & & & & \\
\hline
\end{tabular}

